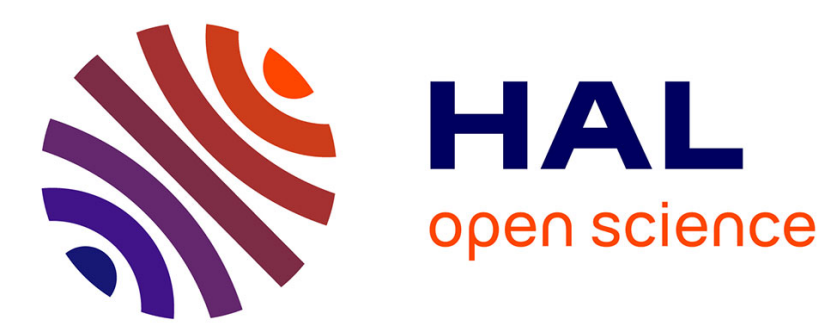

\title{
EFFECT OF ELECTRIC FIELDS ON AUTOIONIZING RESONANCES
}

\author{
D. Kelleher, G. Lombardi, J. Delpech, J. Weiner
}

\section{To cite this version:}

D. Kelleher, G. Lombardi, J. Delpech, J. Weiner. EFFECT OF ELECTRIC FIELDS ON AUTOIONIZING RESONANCES. Journal de Physique Colloques, 1982, 43 (C2), pp.C2-439-C2-441. 10.1051/jphyscol:1982235 . jpa-00221847

\section{HAL Id: jpa-00221847 https://hal.science/jpa-00221847}

Submitted on 1 Jan 1982

HAL is a multi-disciplinary open access archive for the deposit and dissemination of scientific research documents, whether they are published or not. The documents may come from teaching and research institutions in France or abroad, or from public or private research centers.
L'archive ouverte pluridisciplinaire HAL, est destinée au dépôt et à la diffusion de documents scientifiques de niveau recherche, publiés ou non, émanant des établissements d'enseignement et de recherche français ou étrangers, des laboratoires publics ou privés. 


\title{
EFFECT OF ELECTRIC FIELDS ON AUTOIONIZING RESONANCES
}

\author{
D.E. Kelleher, G.G. Lombardi, J.F. Delpech* and J.W. Weiner** \\ National Bureau of Standards, Washington, D.C. 20234, U.S.A. \\ *Institut d'Electronique Fondamentale, Bât. 220, Université de Paris-Sud, \\ 91405 Orsay Cedex, France \\ **university of Maryzand, College Park, MaryZand, U.S.A.
}

We have studied the effect of electric fields on autoionizing (AI) resonances. We have observed the broadening of a relatively sharp AI resonance by field mixing with another much broader resonance. The effect is analogous to the broadening of the metable $2 S$ in Hydrogen by field mixing with the 2P. (1) The AI problem differs, however, in that continua are involved, and AI decay rates (and therefore widths) are typically on the order of $10^{4}$ times larger than radiative decay rates.

We have looked at doubly excited states of $\mathrm{Sr}, \mathrm{Ca}$, and Gd which lie near to but above the ionization limit. In contrast to the field-induced resonances discussed earlier this conference, we consider resonances which are present even at zero field, and observe how their autaionization rates (widths) change as a function of electric field.

The experiments were performed by laser scanning the resonances in a thermal beam between field plates, and detecting the resulting ions with an electron multiplier. Our experiment is complementary to earlier oneis $(2,3)$ which were performed on Rydberg AI levels, where changes in width were observed at level anticrossings. The results we report here are monotonic in the field strength. Also, first order Stark splittings of a sharp Feshbach (AI) resonance in $\mathrm{H}^{-}$were observed by $\mathrm{B}$ int et al. (4)

Our measurements in $\mathrm{Sr}$ were performed on distinctiy non Rydberg $\mathrm{AI}$ resonances. Some such "valence" levels are extremely broad, e.g. Sr 4d6p Tpo, has a width of $475 \mathrm{~cm}^{-1}$ in zero field. (5) In our experiment we scanned over a relatively sharp resonance $\left(1.2 \mathrm{~cm}^{-1}\right.$ in zero field) of opposite parity, $4 \mathrm{~d} 5 \mathrm{~d}{ }^{1} \mathrm{D}_{2}$, which falls energetically in the near wing $\left(E^{P}-E^{D} \simeq 600 \mathrm{~cm}^{-1}\right)$ of the broad resonance. The increase in width of the relatively narrow ${ }^{1} \mathrm{O}_{2}$ resonance became large enough to measure at a field of about $50 \mathrm{kV} / \mathrm{cm}$. Over a range of measurements in $\mathrm{Sr}$ from 50 to $130 \mathrm{kV} / \mathrm{cm}$, a least squares fit through the data yields an electric field induced width $\left[\mathrm{r}_{\mathrm{F}}-\mathrm{T}_{0}\right]=6.5 \times 10^{-10} \mathrm{~F}_{\mathrm{V} / \mathrm{cm}} \pm 0.2$, where $\Gamma_{0}$ is the zero field width in $\mathrm{cm}^{-1}$. We would have liked to extend the measurements to higher field strengths, but even at $10^{5} \mathrm{~V} / \mathrm{cm}$ our apparatus tends to self destruct, and at $F>1.3 \times 10^{5}$ the number of blown amplifiers per data point becomes 
prohibitive.

We compare this result to a simple bound-bound perturbations mixing model, given by Davis and Jacobs, ${ }^{(6)}$ which can be written as

$$
\Gamma_{i}=\frac{d^{2} F^{2}}{\left(E_{i}-E_{j}\right)^{2}+\Gamma_{j}^{2} / 4} \Gamma_{j}
$$

where $\Gamma_{j}$ is the field induced width due to mixing with the much broader level $j, d=e\left\langle\Psi_{i}|z| \Psi_{j}\right\rangle$ is the dipole coupling constant, $F$ represents the field strength and $E_{0 j}$ the energy of the center of the resonance. This is just the quadratic Stark expression with the smeared energy distribution of the $j$ level taken approximately into account by using $E_{j} \rightarrow E_{j}+i \Gamma_{j} / 2$. This zero-order estimate assume the mixing of Lorentzian (infinite) profiles separated by $\Delta E_{i j}>>\Gamma_{j}$. It does not address such questions as the effect of the field on the shape of the profiles, whether the energy $E_{0 j}$ should include the shift due to configuration interaction with the continuum, the case $\Delta E_{i j} \lesssim \Gamma_{j}$, or the effects of continuum mixing. These are all questions which pertain to our experiment, and which will be discussed in an ensuing publication (for an initial effort at a more fundamental approach to this problem, see ref. 7).

Notwithstanding the severe limitations of the bound-bound perturbation model, its predictions are in reasonable agreement with our experimental results. By comparing our results at $10^{5} \mathrm{~V} / \mathrm{cm}$ with eqn. (1), we obtain a dipole matrix el ement $d=21 \mathrm{ea}_{0}$, compared to a Coulomb approximation value ${ }^{(8)}$ of $d=15 \mathrm{ea}_{0}$. (Our Froese-Fischer Hartree-Fock code does not converge for the $4 d 5 d^{l} D_{2}$ state). of course, improved calculations are required before we can conclude much from this relatively good agreement. However, these and related results appear to point consistently to a general feature of field mixing that warrants further theoretical consideration: bound-bound field mixing appears to dominate; continuum-continuum mixing effects have not been observed. This conclusion is consistent with null results we have obtained for other lines in $\mathrm{Sr}$ and $\mathrm{Ca}$, (some of which were significantly sharper than the ${ }^{1} D_{2}$ in $S r$ ) and with the results of other experiments $(2,3,4)$.

Our qualitative interpretation of this observation may be expressed as follows: As Fano pointed out, ${ }^{(9)}$ an AI resonance may be considered as a superposition of discrete ("bound") states $\phi$, and continuum states $\psi_{E}$ :

$$
\Psi_{E}=a_{E} \phi+\int b_{E^{\prime}} \cdot \psi_{E^{\prime}} d^{\prime} E^{\prime}
$$

The width of the resonance is proportional to the configuraion interaction between the discrete and continuum parts: $\Gamma \sim|\langle\phi|H| \psi\rangle|^{2}$, where $H$ is the Hamiltonian for the system. If we turn on an electric field, we will couple states of opposite parity. Three types of coupling arise
(a) bound-bound:
$\left\langle\phi^{0}|z| \phi^{e}\right\rangle$ important
(b) bound-contin: $\left\langle\phi^{0, e_{1}}|z| \psi^{\mathrm{e}, 0}\right\rangle=$ zero 
(c) contin-contin: $\left\langle\psi^{0}|z| \psi^{e}\right\rangle \quad-\quad$ no observed effects

The bound-bound coupling gives rise in lowest order to eqn (1). The boundcontinuum coupling is formally zero because the one electron operator " $z$ " cannot

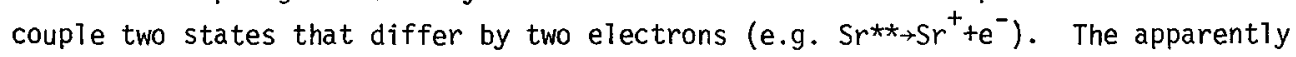
negligible role of continuum-continuum coupling is less straightforward to explain. We note that if one uses a perturbation expansion for the wave functions in a field $F$ :

$$
\begin{aligned}
& \phi^{(0)}(F)=\phi^{0}+F \sum<\phi_{n}^{e}|d| \phi^{0}>\phi_{n}^{e}\left(E-E_{n}\right)^{-1} \\
& \psi_{E}^{(0)}(F)=\psi_{E}^{0}+F \delta<\psi_{E^{\prime}}^{e}|d| \psi_{E^{0}}^{0}>\psi_{E^{\prime}}^{e}\left(E-E^{\prime}\right)^{-1} d E^{\prime}
\end{aligned}
$$

and analogous expression for $\phi^{(\mathrm{e})}, \psi^{(\mathrm{e})}$, (such a perturbation expansion for the continua is thoroughiy unjustified due to the degeneracies involved), we obtain:

$$
\begin{aligned}
& \left|<\phi{ }^{(e)}(F)\right| H_{0}+d \cdot F\left|\psi_{E}^{(e)}(F)>\right|^{2}=\Gamma^{e}+0\left(F^{4}\right) \\
& |<\phi(e)(F)| H_{0}+d \cdot F\left|\psi_{E}^{(0)}(F)>\right|^{2}=F^{2} \mid \Sigma\left(E-E_{n}\right)^{-1}\left\langle\phi_{n}^{e}\left|d_{z}\right| \phi^{0}>\left.V_{n}^{o}\right|^{2}\right. \\
& +F^{2}\left|\delta<\psi_{E^{\prime}}^{e}\right| d_{z}\left|\psi_{E}^{0}>V^{e}\left(E-E^{\prime}\right)^{-1} d E^{\prime}\right|^{2} \\
& +O\left(F^{4}\right)
\end{aligned}
$$

and analogous expressions for $\phi^{(0)}(F)$; where, $F^{\mathrm{e}}$ is the zero field width of the (narrower in our expt.) resonance: $\Gamma^{\mathrm{e}}=2 \pi\left|\mathrm{V}^{\mathrm{e}}\right|^{2}, v^{\mathrm{e}}=\left\langle\phi^{\mathrm{e}}\left|\mathrm{H}_{0}\right| \psi^{\mathrm{e}}\right\rangle$. The important point here is that the bound-bound mixing, $\left\langle\phi^{e}\left|d_{z}\right| \phi^{0}\right\rangle$ is weighted by the large "width" $v^{0}$, while the continuum-continuum is weighted by the sma11 "width" $v^{e}$. In our $\mathrm{Sr}$ experiment, $\Gamma^{\circ} / \Gamma \mathrm{e}_{2350}$. Unfortunately, the validity of this argument suffers from the invalidity of the perturbative expansion for the continuumcontinuum mixing.

We have also observed electric field effects on the Gadolinium AI resonance cited in ref. (10). We observed pronounced field effects at $F>1.5$ volts $/ \mathrm{cm}$ ! While this resonance is relatively isolated and clearly non-Rydbergian, it appears to be configuration mixed with a Rydberg series converging to the first excited state of $\mathrm{Gd}^{+}$. More details will be published elsewhere.

\section{$\underline{\text { References }}$}

(1) G. Lüders, Z. Naturforschg, 5a, 608 (1950).

(2) R.R. Freeman and G.C. Bjorklund, Phys. Rev. Lett. 40, 118 (1978).

(3) K.A. Safinya, J.F. Delpech, T.F. Gallagher, Phys. Rev. A22, 1062 (1980).

(4) H.C. Bryant, et ai., Phys. Rev. Lett. 40, 107 (1978). H.C. Bryant, et al., in "Atomic Physics 7", p. 29, Plenum Press, New York (1981) eds. Ki eppner and Pipkin.

(5) W.R. Garton, et al., J. Phys. B 1,114 (1968).

(6) J. Davis and V.L. Jacobs, Phys. Rev. A12, 2017 (1975),

(7) D.E. Kelleher, in "Spectral Line Shapes 5", 281, Walter de Gruyter, New York (1987), ed. B. Wende.

(8) We thank R.R. Freeman for providing us with the results of this calculation.

(9) U. Fano, Phys. Rev. 124, 1866 (1961).

(10) G.I. Bekov, V.S. Letokhov, O.I. Matveev and V.I. Mishin, JETP Lett. $28,283(1978)$. 